\title{
CORRECTIONS
}

\section{Environmentalists seek to set research agenda on indoor air pollution}

In this news article by Bob Roehr (BMJ 2011;342:d3062, doi:10. 1136/bmj.d3062) we gave the wrong information about Dr John Balbus's workplace and job title. He is the senior adviser for public health at the National Institutes of Health's National Institute of Environmental Health Sciences.

Cite this as: $B M J 2011 ; 342: \mathrm{d} 3679$ 